\title{
АДМИНИСТРАТИВНОЕ САНКЦИОНИРОВАНИЕ КАК ФОРМА ПУБЛИЧНОЙ ДЕЯТЕЛЬНОСТИ: ПОНЯТИЕ И ОСНОВНЫЕ ПРИЗНАКИ
}

\begin{abstract}
Аннотация: В статье рассматривается актуальное в связи с проводимой административной реформой понятие административного санкционирования, на основе анализа имеющихся научных формулировок дается его определение как формы административной деятельности, представляющей собой часть административного процесса и включающей в себя лицензионно-разрешительные, регистрационные, удостоверительные, согласовательные виды деятельности. Автор рассматривает основные признаки административного санкционирования. Автором выделяются виды административного санкционирования: лицензирование и выдача разрешений, государственная регистрация, административное удостоверение (включая государственную аккредитацию и аттестацию), административное согласование. Автором анализируются имеющиеся в научной литературе понятия, относящиеся к административной деятельности анализируется соотношения понятий "административное санкционирование", "государственная и муниципальная услуга", систематизируются основные признаки административного санкционирования, дается классификация его видов. Автором впервые дается определение понятия "административное санкционирование", выделяются основные признаки данного понятия: состоит из совокупности административных действий, является положительным административным регулированием, носит внешневластный, правоприменительный, регулятивный, процедурный характер, осуществляется по инициативе частных лии, оканчивается принятием санкционирующего акта, посредством административного санкционирования реализуется дозволительный метод административного права , приводится авторская классификация видов административного санкционирования.

Ключевые слова: административная реформа, административное санкционирование, лицензия, разрешение, регистрация, удостоверение, согласование, дозволение, внешневластный характер, правоприменительный характер.
\end{abstract}

$\mathrm{H}$ а протяжении более чем десяти лет в российском обществе осуществляется административная реформа. В ходе реформы происходит широкомасштабная унификация и типизация деятельности органов исполнительной власти. Деятельность административных органов в настоящее время конкретизируется, классифицируется и регламентируется. Сопутствующим явлением административной реформы является уточнение понятийного аппарата административного права, в том числе появление новых понятий. В связи с этим, на наш взгляд, право на существование имеет и претендует на самостоятельное место в ряду этих понятий категория «административное санкционирование» ${ }^{1}$.

1 Данная категория впервые была предложена Стаховым А.И. в 2007 году. См.: Административно-публичное обеспечение безопасности в Российской Федерации: дис. ... канд. юрид. наук: 12.00.14. М., 2007. 429 с. В дальнейшем понятие «административное санкционирование» также получило развитие в трудах Киселева Ф.Н. См., например: Административное санкционирование как метод обеспечения безо-
Важнейшее значение при проведении административной реформы имеет четкое понимание специфики различных форм деятельности органов исполнительной власти. Ввиду повышения технологичности их деятельности такая специфика получает закрепление в нормах права. Необходимо отметить, что стандартизация является характерной тенденцией для всех видов профессиональной деятельности. В большинстве сфер общественной жизни наблюдается разработка профессиональных стандартов². Деятельность по государствен-

пасности в Российской Федерации: дис. ... канд. юрид. наук: 12:00:14. M.,2011. 2010 c.

2 Федеральным законом от 03.12.2012 № 236-Ф3 «О внесении в Трудовой кодекс Российской Федерации и статью 1 Федерального закона «О техническом регулировании» в Трудовой кодекс Российской Федерации введена статья 195.1, в которой дается определение профессионального стандарта как характеристики квалификации, необходимой работнику для осуществления определенного вида профессиональной деятельности, а также устанавливается, что порядок разработки, утверждения и применения профессиональных 
ному управлению не исключение, свидетельством чему является разработка регламентов и стандартов предоставления государственных и муниципальных услуг и осуществления государственных и муниципальных функций.

В целях определения категории «административное санкционирование» необходимо обозначить место административного санкционирования в управленческом процессе, соотношения понятия «административное санкционирование», с одной стороны, и «административный процесс», «формы», «виды», «методы административной деятельности», с другой.

Теория административного процесса исследуется с 60-х гг. XX века. В современной науке сложились два основных подхода к его пониманию. Первый состоит в том, что под административным процессом понимается вся деятельность административных органов (внешневластная и внутриорганизационная). Согласно второму подходу, административный процесс переносится сугубо в юрисдикционную деятельность по рассмотрению и разрешению административных дел.

По мнению Н.М. Конина, Ю.Н. Старилова, административный процесс шире административной юрисдикции. «Представляется, что административно-процессуальную деятельность нельзя ограничивать только сферой административной юрисдикции. Юрисдикционная деятельность является частью не только процессуальной, но и иной исполнительно-распорядительной деятельности; она осуществляется не всеми органами исполнительной власти, в связи с чем не может быть тождественной административно-процессуальной деятельности. В настоящее время общепризнанным в юридической науке является положение о том, что процессуальные нормы обеспечивают реализацию норм материальных, и наоборот, нормы права, закрепляющие порядок реализации материальных норм, представляет собой нормы процессуальные. Данное общетеоретическое положение без каких-либо исключений распространяется и

стандартов, а также установления тождественности наименований должностей, профессий и специальностей, содержащихся в едином тарифно-квалификационном справочнике работ и профессий рабочих, едином квалификационном справочнике должностей руководителей, специалистов и служащих, наименованиям должностей, профессий и специальностей, содержащихся в профессиональных стандартах, устанавливается Правительством Российской Федерации с учетом мнения Российской трехсторонней комиссии по регулированию социально-трудовых отношений. на нормы административного права» ${ }^{3}$. С данной точкой зрения сложно не согласиться, учитывая широкомасштабную деятельность по составлению регламентов государственных и муниципальных услуг и функций, содержащих в себе значительную долю процессуальных норм.

Отдельными составляющими административного процесса выступают административные процедуры. В Федеральном законе от 27.07.2010 № 210-Ф3 «Об организации предоставления государственных и муниципальных услуг» административные процедуры оформляются в отдельный раздел административного регламента. Так, согласно подпункту 3 пункта 2 статьи 12 указанного закона структура административного регламента должна содержать, в том числе, раздел, устанавливающий состав, последовательность и сроки выполнения административных процедур, требования к порядку их выполнения, в том числе, особенности выполнения административных процедур в электронной форме.

Таким образом, очевидно, что административная процедура представляет собой определенный порядок действий для достижения определенных административно-правовых целей.

Административное санкционирование является частью административного процесса и осуществляется с использованием определенных процедур. Данную точку зрения разделяет А.Б. Агапов. По его мнению, «публичное санкционирование коммерческой деятельности предполагает сочетание взаимообусловленных процедур ${ }^{4}$.

Законодательством Российской Федерации, субъектов Российской Федерации и органов местного самоуправления подробно регламентируется порядок осуществления регистрационных, разрешительных, удостоверительных и иных видов административной деятельности, осуществляемой в рамках административного санкционирования.

Таким образом, понятие «административное санкционирование» входит в понятие «административный процесс».

Деятельность административных органов в ходе административного процесса осуществляется в определенных типичных формах.

«Под формами управленческой деятельности обычно понимают способы выражения ее со-

См.: Административное право России. Под ред. Конина Н.М., Старилова Ю.Н. М., 2010. С. 457- 458.

4 См.: Агапов А.Б. Административное право. М., 2011. C. 470 . 
держания, систему внутренне взаимосвязанных способов осуществления функций управления, определенное внешнее выражение конкретных управленческих действий как части управленческой деятельности» ${ }^{5}$.

Ю.Н. Старилов под правовой формой управления предлагает понимать «внешне выраженное и юридически оформленное действие органа управления публичной власти (или должностного лица), осуществляемое в пределах его компетенции и вызывающее определенные правовые последствия. Форма управления - это внешнее выражение практической реализации функций и методов управления, самого управляющего воздействия, конкретных действий, производимых в процессе осуществления исполнительной власти, административной деятельности», «...форма управления это внешнее выражение практической реализации функций и методов управления, самого управляющего воздействия, конкретных действий, производимых в процессе осуществления исполнительной власти или всей административной деятельности... Формы управления призваны обеспечить наиболее целесообразное выполнение функций управление и достижение целей управления с наименьшими затратами сил, средств и времени; от формы управления зависят успех и конкретные результаты управленческой деятельности... Основными понятиями, позволяющими рассматривать термин «форма управления», являются «цели управления», «функции управления», «задачи управления», «полномочия», «компетенция». Данные понятия обусловливают также выбор методов управления (способов управленческого воздействия субъекта управления на объекты управления) в конкретной управленческой ситуации. Целям управления подчинены все используемые субъектами управления формы управления. Посредством форм управления органы реализуют свои полномочия, соответствующие установленной в нормативных актах компетенции этих органов. Формы управления есть средство реализации управленческих функций для достижения целей управления. Функции управления определяют основное содержание управленческой деятельности» ${ }^{6}$.

Выделение тех или иных форм административной деятельности условно. К примеру, Н.М.

\footnotetext{
5 См.: Конин Н.М. Административное право России в вопросах и ответах. М., 2007. С. 78.

6 См.: Административное право России. Под ред. Конина Н.М., Старилова Ю.Н. М., 2010. С. 348-349.
}

Конин наряду с административным нормотворчеством и административным исполнительством выделяет такую форму административной деятельности как административное распорядительство, включающую в себя «принятие аппаратом исполнительной власти индивидуальных (ненормативных, административных) правовых актов управления, которые представляют собой односторонние властные волевые действия органов исполнительной власти, их структурных подразделений, должностных лиц, совершаемые ими в процессе выполнения управленческих функций и направленные на установление, изменение или прекращение конкретных правоотношений, указанных в самом этом акте субъектов» ${ }^{7}$.

На наш взгляд, административное санкционирование представляет собой одну из самостоятельных форм управления, имеет свои цели, задачи, содержание и относится к категории юридически значимых действий.

Что касается соотношения понятия «административное санкционирование» и «метод административной деятельности», то, на наш взгляд, оно состоит в следующем.

Среди общеправовых методов выделяются основные три: предписание, запрет и дозволение. При этом предписание представляет собой метод правового регулирования, предполагающий возложение на субъекта управленческой деятельности обязанностей совершения определенных действий в условиях, предписанных административно-правовой нормой; запрет - метод правового регулирования, предполагающий возложение обязанностей на участников управленческих отношений воздержаться от определенного варианта поведения под угрозой применения мер государственного принуждения; дозволение - метод правового регулирования, предоставляющий участникам управленческих отношений возможность самим выбирать наиболее приемлемый вариант поведения в тех пределах, которые определены нормами административного права.

Как справедливо отмечает Н.В.Макарейко, «в настоящее время диспозитивные средства правового регулирования начали применяться все более широко, что обусловлено тенденцией децентрализации государственного управления» ${ }^{8}$.

\footnotetext{
См.: Конин Н.М. Административное право России в вопросах и ответах. М., 2007. С. 80.

8 См.: Макарейко Н.В. Административное право. Конспект лекций. М., 2011. С. 16.
} 
На наш взгляд, административному санкционированию присущ именно дозволительный метод административного права, поскольку властными органами дается разрешение на то или иное поведение подвластных лиц.

Для целей формирования эффективной системы и структуры федеральных органов исполнительной власти Указом Президента Российской Федерации от 09.03.2004 г. № 314 «О системе и структуре федеральных органов исполнительной власти» выделены четыре разновидности функций федеральных органов исполнительной власти:

актов;

- функция по контролю и надзору;

- функция по управлению государственным имуществом;

- $\quad$ функция по оказанию государственных услуг.

Исходя из понимания функции административных органов как определенной роли данного органа в той или иной сфере (например, в сфере строительства, здравоохранения, образования), считаем необходимым использовать данную классификацию исключительно в целях Указа Президента Российской Федерации № 314.

В связи с этим, административное санкционирование может осуществляться в ходе осуществления различных функций административных органов.

С нашей точки зрения, выделение функций по предоставлению государственных услуг весьма условно и проводится, главным образом, с точки зрения инициативы предоставления услуг, исходящей от заказчика - физического или юридического лица (их объединения). Для удобства понимания подвластными субъектами (физическими и юридическими лицами) сути данной функции органов исполнительной власти, простоты ее использования в обыденной жизни, в целях упрощения взаимодействия органов власти и населения в обиход введено данное понятие, по большому счету не имеющее отношения к отраслям публичного права, а заимствованное из сферы гражданского права.

Среди существенных признаков административного санкционирования можно выделить следующие:

1. Административное санкционирование, как указывалось выше, представляет собой форму административной деятельности, состоящую из совокупности административных действий.

«Управленческая деятельность государственных органов и органов местного самоуправления (государственных и муниципальных служащих, должностных лиц) осуществляется в определенных формах, каждая из которых обусловлена специфическими задачами и функциями управления и имеет особое содержание. Всякая деятельность по управлению характеризуется собственным содержанием, т.е. конкретными связями, принципами, процессами, участниками и элементами; всякое содержание управления имеет конкретную форму своего внешнего выражения»9.

Ю.Н. Старилов предлагает следующую систему форм управленческих действий (форм управления):

- издание нормативных правовых актов;

- издание ненормативных и индивидуальных правовых актов;

- заключение публично-правовых договоров (например, административных договоров, международных соглашений);

- совершение юридически значимых действий или действий юридического характера на основе закона или на основе изданного правового акта управления (составление административных протоколов, проведение государственной регистрации, осуществление властных распорядительных и контрольных мероприятий, выдача официальных документов, позволяющих осуществлять определенный вид деятельности);

- осуществление организационных действий;

- выполнение материально-технических действий. Следуя вышеуказанной классификации Ю.Н.Старилова, административное санкционирование относится к четвертой группе форм управления - совершению юридически значимых действий или действий юридического характера и может сопровождаться изданием индивидуальных правовых актов.

2. Административное санкционирование является положительным административным регулированием, то есть направлено на возникновение новых правоотношений в регулируемой сфере, имеет позитивный созидательный характер, в результате чего правомерное поведение (действия) частных лиц осуществляется. Тогда как, напротив, административное пресечение направлено на остановку неправомерного поведения, его прекращение. Административное санкционирование это всегда начало, юридический факт, вызывающий к жизни определенные правоотношения.

9 См.: Административное право России. Под ред. Конина Н.М., Старилова Ю.Н. М., 2010. С. 348-349. 
3. Административное санкционирование носит внешневластный характер, направлено на регулирование отношений с подвластным субъектом.

В ходе административного санкционирования взаимодействуют две группы субъектов: уполномоченный орган публичной исполнительной власти (субъект управления), с одной стороны, и заинтересованное в осуществлении данного юридического действия физическое или юридическое лицо, обратившееся в орган исполнительной власти (объект управления).

Данные субъекты правоотношений по административному санкционированию находятся в различном правовом положении: властный характер полномочий первого проявляется в возможности привлечь второго к установленной ответственности за нарушение требований и условий, согласно которым выдан соответствующий акт административного санкционирования.

4. Деятельность по административному санкционированию носит правоприменительный характер, то есть имеет строго индивидуальный характер, основывается на нормах законодательства и осуществляется во исполнение его положений.

При этом в ходе административного санкционирования применяются как положения законов, так и подзаконных актов.

5. Административное санкционирование имеет регулятивный характер, то есть направлено на регулирование общественных отношений путем предоставления участникам прав и возложения на них обязанностей.

6. Административное санкционирование осуществляется, как правило, по инициативе частных физических и юридических лиц, то есть несмотря на общеобязательный властный характер, возбуждение административного дела зависит от волеизъявления подвластного субъекта.

В этом состоит особенность государственного регулирования рыночной экономики, при котором излишнее вмешательство государства в экономику не допускается.

Однако существуют случаи, когда административное санкционирование осуществляется в ходе взаимодействия различных административных органов. Речь идет об обязательных согласованиях того или иного административного решения несколькими административными органами.

7. Процедурный характер: применение административного санкционирования регламентировано нормами права. Существенными стадиями административного санкционирования являются эксперти- за проверки соответствия соблюдения требований законодательства, оценка соблюдения этих требований и выдача заключения по данному вопросу.

8. Административное санкционирование оканчивается принятием того или иного административного решения по результатам представленных документов и материалов (санкционирующего акта).

9. В административном санкционировании реализуется дозволительный метод административного права.

Как указывалось выше, административное санкционирование носит правопредоставительный характер, поскольку предоставляет подвластному субъекту - физическому или юридическому лицу, обратившемуся в орган исполнительной власти, - определенные права, возможность действовать в рамках действующего законодательства.

В форме административного санкционирования воплощаются конкретные виды административного санкционирования.

По мнению Д.Н. Киселева, «из анализа действующего административного законодательства в сфере обеспечения безопасности можно составить ряд типизированных процедур санкционирования, раскрывающих содержание таких административно-правовых методов обеспечения безопасности, как разрешительный, удостоверительный и регистрационный» ${ }^{10}$.

Так, в содержании разрешительного метода указанный автор выделяет типизированные административные процедуры официального признания допустимыми действий и решений физических и юридических лиц по приведению в соответствие с общеобязательными правилами (условиями и

требованиями) безопасности отдельных видов техногенных и природных источников опасности. К таковым процедурам относятся:

1. процедура предоставления лицензии на использование техногенного или природного источника опасности;

2. процедура предоставления специального разрешения на использование техногенного или природного источника опасности.

В обобщенном виде приведенные административные процедуры можно вышеуказанный автор называет разрешительными процедурами административного санкционирования.

10 Киселев Д.Н. О систематизации процедур административного санкционирования в сфере обеспечения безопасности//Административное право и процесс, № 5, 2011. С. 58. 
На наш взгляд, к самостоятельным видам административного санкционирования можно отнести следующие:

1. лицензирование и выдача разрешений на право осуществлять определенные действия, заниматься определенной деятельностью;

2. государственная регистрация;

3. административное удостоверение (сюда же относится государственная аккредитация и аттестация);

4. административное согласование.

Таким образом, под административным санкционированием мы предлагаем понимать реализуемую в рамках административного процесса специ- фическую форму административной деятельности, представляющую собой часть административного процесса и включающую в себя лицензионно-разрешительные, регистрационные, удостоверительные, согласовательные виды деятельности, в ходе которой происходит оценка потенциальных правоотношений частных лиц либо оценка соответствия разрабатываемого документа предъявляемым к нему требованиям и выдается заключение (отказывается в выдаче заключения) дозволительного свойства, позволяющее осуществлять определенную деятельность (совершать определенные действия), имеющая правоприменительный, внешневластный характер положительного регулирования.

\section{Библиография:}

1. Административное право России. Под ред. Конина Н.М., Старилова Ю.Н. М.: Норма: Инфра-М, 2010.784 с.

2. Агапов А.Б. Административное право. М.: Юрайт, 2011. 820 с.

3. Конин Н.М. Административное право России в вопросах и ответах. М.: Проспект, 2009. 256 с.

4. Макарейко Н.В. Административное право. Конспект лекций. М.: Юрайт, 2011. 191 с.

5. Киселев Д.Н. О систематизации процедур административного санкционирования в сфере обеспечения безопасности //Административное право и процесс, № 5, 2011. С. 58.

6. Административно-публичное обеспечение безопасности в Российской Федерации: дис. ... канд. юрид. наук: 12.00.14. М., 2007. 429 c.

7. Административное санкционирование как метод обеспечения безопасности в Российской Федерации: дис. ... канд. юрид. наук: 12:00:14. М.,2011. 210 с.

8. К.И.Головщинский, А.С.Данилов и др. Административная реформа и проблемы государственного управления. М., 2008. 276 c.

9. Федеральный закон от 27.07.2010 № 210-Ф3 (ред. от 21.07.2014) «Об организации предоставления государственных и муниципальных услуг»// «Российская газета», № 168, 30.07.2010, «Собрание законодательства РФ», 02.08.2010, № 31, ст. 4179.

10. Распоряжение Правительства Российской Федерации от 25.10.2005 № 1789-р (ред. от 10.03.2009) «О Концепции административной реформы в Российской Федерации в 2006-2010 годах».

\section{References (transliterated):}

1. Administrativnoe pravo Rossii. Pod red. Konina N.M., Starilova Yu.N. M.: Norma: Infra-M, 2010. 784 s.

2. Agapov A.B. Administrativnoe pravo. M.: Yurait, 2011. $820 \mathrm{~s}$.

3. Konin N.M. Administrativnoe pravo Rossii v voprosakh i otvetakh. M.: Prospekt, 2009. 256 s.

4. Makareiko N.V. Administrativnoe pravo. Konspekt lektsii. M.: Yurait, 2011. $191 \mathrm{s.}$

5. Kiselev D.N. O sistematizatsii protsedur administrativnogo sanktsionirovaniya v sfere obespecheniya bezopasnosti// Administrativnoe pravo i protsess, № 5, 2011. S. 58.

6. Administrativno-publichnoe obespechenie bezopasnosti v Rossiiskoi Federatsii: dis. ... kand. yurid. nauk: 12.00.14. M., 2007. $429 \mathrm{~s}$.

7. Administrativnoe sanktsionirovanie kak metod obespecheniya bezopasnosti v Rossiiskoi Federatsii: dis. ... kand. yurid. nauk: 12:00:14. M.,2011. $210 \mathrm{c}$.

8. K.I.Golovshchinskii, A.S.Danilov i dr. Administrativnaya reforma i problemy gosudarstvennogo upravleniya. - M., 2008. $276 \mathrm{~s}$.

9. Federal'nyi zakon ot 27.07.2010 № 210-FZ (red. ot 21.07.2014) «Ob organizatsii predostavleniya gosudarstvennykh i munitsipal'nykh uslug»// «Rossiiskaya gazeta», № 168, 30.07.2010, «Sobranie zakonodatel'stva RF», 02.08.2010, № 31, st. 4179.

10. Rasporyazhenie Pravitel'stva Rossiiskoi Federatsii ot 25.10.2005 № 1789-r (red. ot 10.03.2009) «0 Kontseptsii administrativnoi reformy v Rossiiskoi Federatsii v 2006-2010 godakh». 